$62.5^{\circ} \mathrm{C}$ the holder pasteurisation time of 30 minutes seems unnecessary. We were not concerned about less thermolabile organisms, since they tend to be of unlikely pathogenicity or spore-forming. Mycobacteria are not common pathogens in human milk. We intend to investigate whether a shorter heating time will conserve a higher proportion of immunologically active substances in milk. Ford et $\mathrm{al}^{7}$ reported that heating milk for $\mathbf{3 0}$ minutes at $62.5^{\circ} \mathrm{C}$ reduced the IgA titre by $20 \%$ and destroyed the small amount of IgM and most of the lactoferrin.

We thank Miss Valerie Hooton for her constant help in supervising the experimental work.

\section{References}

${ }^{1}$ British Medical fournal, 1978, 1, 1372.

2 Lucas, A, and Roberts, C D, British Medical fournal, 1979, 1, 80.

${ }^{3}$ Baker, F J, and Breach, M R, Handbook of Bacteriological Technique, 2nd edn, p 209. London, Butterworths, 1967.

${ }^{4}$ Cruickshank, R, et al, Medical Microbiology, 12th edn, vol 2, p 307. Edinburgh, Churchill Livingstone, 1975.

5 Armitage, P, Statistical Methods in Medical Research, p 66. Oxford and Edinburgh, Blackwell Scientific Publications, 1971.

${ }^{6}$ Raptopoulou-Gigi, M, Marwick, K, and McClelland, D B L, British Medical Fournal, 1977, 1, 12.

${ }^{7}$ Ford, J E, et al, fournal of Pediatrics, 1977, 90, 29.

(Accepted 11 September 1979)

\title{
How reliable is determination of ulcer size by endoscopy?
}

\author{
A SONNENBERG, M GIGER, L KERN, C NOLL, K STUBY, K B WEBER, A L BLUM
}

British Medical fournal, 1979, 2, 1322-1324

\section{Summary and conclusions}

The surface areas of 23 artificial ulcers in a rubber manikin and of 35 ulcers in 35 consecutive patients admitted for endoscopy of the upper gastrointestinal tract were estimated by six endoscopists. Of the 138 estimations made in the manikin $80 \%$ underestimated the true size of the ulcer: the mean $( \pm S D)$ was $-29 \pm 40 \%$. The largest and the smallest estimate of the same ulcer by different endoscopists varied on average by a factor of $4.5 \pm 3.8$, and the estimates by the same endoscopists of ulcers with the same size varied by a factor of $2 \cdot 3 \pm 0.6$. In the patients the scatter of the estimates was even larger, the mean factor being $7 \cdot 8 \pm 6 \cdot 3$. Changes in ulcer size are therefore an unsuitable criterion for assessing ulcer healing. Even if consecutive examinations are performed by the same endoscopist, changes in ulcer area smaller than by a factor of 3 are not discernible.

\section{Introduction}

In many controlled clinical trials of treatment for peptic lesions changes in the size of an ulcer have been used as an index of ulcer healing. ${ }^{1-7}$ We decided to test the reliability of the determination of ulcer size by fibreoptic endoscopy.

\section{Methods}

In-vitro studies-In a rubber manikin consisting of head, oesophagus, stomach, and duodenum ${ }^{8}$ (OGI Phantom, Coburger Lehrmittelanstalt, W Germany) 23 artificial, consecutively numbered peptic lesions were produced. The lesions were excavated with a sharp spoon and painted white with water-insoluble paint. The two

Triemli Hospital, CH-8063 Zurich, Switzerland

A SONNENBERG, MD, physician

M GIGER, MD, physician

L KERN, MD, physician

C NOLL, MD, physician

K STUBY, MD, physician

$\mathrm{K}$ B WEBER, MD, physician

A L BLUM, MD, physician largest orthogonal diameters ( $a$ and $b$ ) of each ulcer were measured with a vernier caliper. The area of the ulcer $(A)$ was calculated as:

$$
\mathrm{A}=\frac{\pi \mathrm{ab}}{4}
$$

The areas of the ulcers were estimated on six different days by six endoscopists using a fibreoptic endoscope. Three "experienced" endoscopists had performed more than 1000 endoscopies before entering the trial, and three "beginners" had performed between 100 and 500 endoscopies. No endoscopist had access to the values determined by the others. The endoscopies were performed with the endoscopes GIF D II, GIF P II, and GIF K from Olympus. Every endoscopist was free to choose the instrument(s) he liked. Usually several instruments were used simultaneously. The width of closed and opened biopsy forceps served as reference length. The deviation (D) of the estimated ulcer area ( $\left.A^{\prime}\right)$ from the true ulcer area (A) was calculated as follows:

$$
\mathrm{D}=\frac{\mathrm{A}-\mathbf{A}^{\prime}}{\mathrm{A}}
$$

The absolute value of $\mathrm{D}$ ([D]) was named absolute deviation.

In-vivo study-In 35 patients with an ulcer but no other disease who gave informed consent and tolerated endoscopy well the size of a peptic lesion in stomach or duodenum was estimated by the same endoscopists who had participated in the in-vitro study. To estimate the size of the ulcer every endoscopist was handed the endoscope and manoeuvred it by himself. He then noted the ulcer size on a sheet, dropped the sheet into a locked letter box, and left the room without telling others his findings. The area of the ulcer was calculated in the same way as for the artificial ulcers. In five additional patients ulcers were measured with a measuring rod (ACMI), which could be inserted through the biopsy channel.

Comparison of in-vivo and in-vitro results-Since no information on the true size of the patients' ulcers was obtainable, the following values were used which could be obtained for both the artificial and the real ulcers. An assessment of scatter (S) of the data was the ratio of the standard deviation (SD) over the average estimate of each ulcer area $\left(\overline{\mathrm{A}}^{\prime}\right): \mathrm{S}=\mathrm{SD} / \overline{\mathrm{A}}^{\prime}$. A second assessment of scatter was the ratio $(R)$ of the largest $\left(A^{\prime}{ }_{\max }\right)$ over the smallest $\left(A^{\prime} \min \right)$ estimate of the ulcer size: $R=A^{\prime}{ }_{\max } / A^{\prime}{ }_{m ! n}$. The estimation characteristic $(C)$ of each endoscopist was described by the deviation of his personal mean of 35 estimates (m) from the mean of all 210 estimates (M): $\mathrm{C}=(\mathrm{m}-\mathrm{M}) / \mathrm{M}$.

\section{Results}

In-vitro studies-Of the 138 estimates of ulcer size, $111(80 \%)$ were too small, and this tendency to underestimate ulcer size was statistically significant $\left(\chi^{2}=61 ; \mathrm{Df}=2 ; \mathrm{P}<0.001\right)$. In only 18 cases 
$(13 \%)$ was the estimate too large. The mean values of deviation, absolute deviation, scatter, and ratio of the largest over the smallest estimate are shown in table I. Three groups of three ulcers were of identical size. The $R$ value for these nine ulcers by the same endoscopist ranged from 1.8 to 3.6 and was on average $2 \cdot 3 \pm 0.6$. Both the three experienced endoscopists and the three beginners underestimated the ulcers (by $-40 \pm 28 \%,-40 \pm 36 \%,-35 \pm 23 \%$ and by $-41 \pm 23 \%,-11 \pm 59 \%,-4 \pm 41 \%$ respectively). The ulcers' size, shape, and location had no statistically significant influence on accuracy of estimation (table II).

TABLE I-Average values $( \pm S D)$ and ranges of deviation $(D)$, absolute deviation $([D])$, scatter $(S)$, and ratio $(R) . A^{\prime}$ refers to estimated ulcer area, and $A$ refers to known ulcer area in vitro

\begin{tabular}{|c|c|c|}
\hline & $\begin{array}{l}\text { In vitro } \\
(n=23)\end{array}$ & $\begin{array}{l}\text { In vivo } \\
(\mathrm{n}=35)\end{array}$ \\
\hline$D=\frac{A^{\prime}-A}{A}$ & $\begin{array}{c}-29 \pm 40 \% \\
(-93-+140 \%)\end{array}$ & \\
\hline$[D]=\frac{\left[A^{\prime}-A\right]}{A}$ & $\begin{array}{c}42 \pm 12 \% \\
(0-+140 \%)\end{array}$ & \\
\hline$S=\frac{S D}{\bar{A}^{\prime}}$ & $\begin{array}{c}47 \pm 19 \% \\
(20-89 \%)\end{array}$ & $\begin{array}{l}56 \pm 22 \% \\
(6-108 \%)\end{array}$ \\
\hline $\mathbf{R}=\frac{\mathbf{A}_{\text {max }}^{\prime}}{\mathrm{A}_{\text {min }}^{\prime}}$ & $\begin{array}{c}4.5 \pm 3 \cdot 8 \\
(1.5-20 \cdot 0)\end{array}$ & $\begin{array}{c}7 \cdot 8 \pm 6 \cdot 3^{*} \\
(1 \cdot 2-26 \cdot 8)\end{array}$ \\
\hline
\end{tabular}

$* P<0.05$.

TABLE II-Influence of size, shape, and location on the absolute deviation ([D]) and the scatter $(S)$ of estimates of ulcer size in vitro and in vivo. Values are percentages

\begin{tabular}{ccccccc}
\hline & \multicolumn{2}{c}{ Size } & \multicolumn{2}{c}{ Shape } & \multicolumn{2}{c}{ Location } \\
\cline { 2 - 7 } & $\left\langle 100 \mathrm{~mm}^{2} \geqslant 100 \mathrm{~mm}^{2}\right.$ & Regular & Irregular & Stomach & Duodenum \\
\hline \multicolumn{7}{c}{ In vitro $(n=23)$} \\
[D] & $44 \pm 10$ & $37 \pm 14$ & $44 \pm 9$ & $41 \pm 14$ & $40 \pm 11$ & $49 \pm 11$ \\
$S$ & $51 \pm 19$ & $39 \pm 19$ & $49 \pm 18$ & $45 \pm 21$ & $44 \pm 18$ & $55 \pm 24$ \\
No of ulcers & 16 & 7 & 11 & 12 & 17 & 6 \\
S & $62 \pm 18$ & $50 \pm 25$ & $54 \pm 22$ & $66 \pm 20$ & $53 \pm 22$ & $64 \pm 22$ \\
No of ulcers & 18 & 17 & 29 & 6 & 26 & 9 \\
\hline
\end{tabular}

In-vivo studies-The estimated values obtained by the three experienced endoscopists were larger than those of the three beginners $(+18 \%,+4 \%,+13 \%$ and $-26 \%,+21 \%,-29 \%)$. One beginner who produced the largest underestimation in the manikin delivered the largest values in patients. All other endoscopists had similar ranks of estimation for both real and artificial ulcers (see figure). The ratio $\mathrm{R}$ was larger in vivo than in vitro $(t=2 \cdot 21$ by unpaired Student's $t$-test $; \mathrm{P}<0.05$; table I). The shape and the location of the

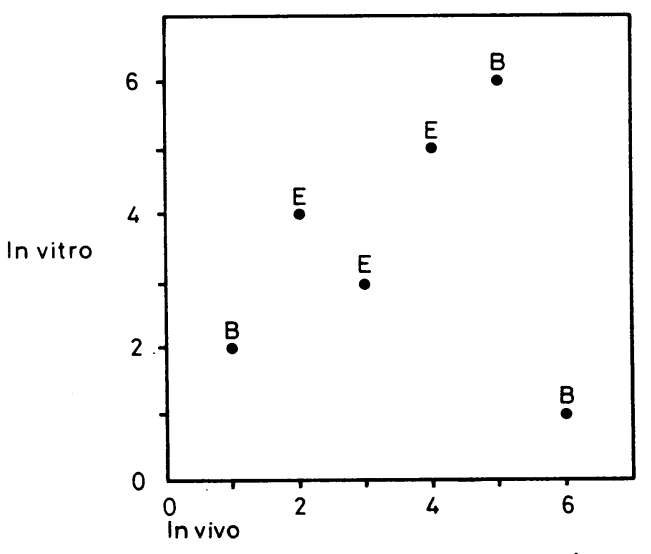

Correlation between each endoscopist's estimations in vivo and in vitro. $\mathrm{B}=$ Beginner endoscopist. $\mathrm{E}=$ Experienced endoscopist. ulcer had no statistically significant influence on the accuracy of estimation (table II). There was a negative linear correlation between the ulcer size and scatter of the estimations $(r=0.49 ; P<0.01)$. In five additional patients 30 estimations were made using a rod with a $2-\mathrm{mm}$ scale. The results were similar to those obtained with the biopsy forceps : $S$ was $59 \pm 28 \%$ and $R$ was $4 \cdot 6 \pm 4 \cdot 5$.

\section{Discussion}

In many randomised trials on the effect of anti-ulcer drugs healing has been assessed by measuring the size of the ulcers before and after treatment. ${ }^{1-7}$ The accuracy and reproducibility of endoscopically assessed ulcer size has, however, never been examined. Because of the optical distortion in all commercially available fibreoptic endoscopes ${ }^{9}{ }^{10}$ and because of the lack of stereoscopic image ${ }^{11} 12$ errors in measurement are likely to occur. In this study we examined the reliability of endoscopic measurement of ulcer size. Since the true size of an ulcer cannot be measured in a patient, an experiment was devised in which ulcer-like lesions were produced in the stomach of a rubber manikin.

Ulcer sizes in the manikin were underestimated in $80 \%$ of the cases by both experienced endoscopists and those still in training. The range of individual error was considerable. In one case the estimated ulcer size was more than 14 times smaller than the actual ulcer while, on the other hand, the maximum overestimation was 2.4 times that of the actual ulcer size. To evaluate the reproducibility of measurements by each endoscopist, three groups of three ulcers of identical size and shape were produced. In this group of ulcers the smallest estimate differed from the largest estimate on a mean factor of $2 \cdot 3$, showing that the endoscopists not only underestimated ulcer size but were also inconsistent in their estimations. On the other hand, the size, shape, and location of the ulcer and the experience of the endoscopist had no significant effect on the accuracy of the estimates.

In a second series of experiments ulcer size was estimated in vivo. Although the true size of an ulcer cannot be assessed the in-vivo data may in conjunction with the in-vitro data allow some conclusions to be drawn. Five of the six endoscopists showed similar behaviour in vivo and in vitro. The remaining endoscopist-a trainee-showed the least degree of underestimation in vitro but consistently produced the lowest estimates in vivo. The ratio of the largest to the smallest estimates was about two times greater in vivo than in vitro. This reflects the great difficulty of estimating ulcer size in a pliable organ, particularly when the measurement is performed hurriedly. Since the endoscopists tended to relate the inaccurate measurements to the biopsy forceps used as reference length a specific measuring rod was introduced. Nevertheless, use of the rod produced no statistically significant improvement in accuracy.

Our findings show that estimation of ulcer size by endoscopy is very inaccurate even when performed by expert endoscopists. If used at all, measurements at subsequent endoscopies in the same patient should be performed by the same endoscopist. Nevertheless, it is advisable not to use changes in ulcer size as an index of the effect of anti-ulcer drugs, but to use instead complete healing of the ulcer as a criterion. This on its own may be difficult ${ }^{13}$ because the macroscopical aspects of an ulcer site do not always allow an assessment of whether an ulcer is completely healed to be made, but errors are less likely to occur than with a method which gives the false impression of scientific accuracy.

\section{References}

1 Bader, J P, et al, in Cimetidine, ed W L Burland and M A Simkins, p 287. Amsterdam, Excerpta Medica, 1977.

${ }^{2}$ Domschke, W, Domschke, S, and Demling, L, in Cimetidine, ed W L Burland and M A Simkins, p 217. Amsterdam, Excerpta Medica, 1977. 
3 Dyck, W P, et al, Gastroenterology, 1978, 74, 410.

4 Englert, E, et al, Gastroenterology, 1978, 74, 416.

${ }^{5}$ Hentschel, E, Schütze, K, and Havelec, L, Wiener Klinische Wochenschrift, 1979, 91, 53.

6 Peter, P, et al, Deutsche medizinische Wochenschrift, 1978, 103, 1163.

7 Scheurer, U, et al, Gastroenterology, 1977, 72, 838.

${ }^{8}$ Classen, M, and Ruppin, H, Endoscopy, 1974, 6, 127.

${ }^{9}$ Lindner, H, and Fintelmann, V, Leber Magen Darm, 1971, 1, 155.
${ }^{10}$ Lindner, H, Zeitschrift für Gastroenterologie, 1972, 10, 387.

${ }^{11}$ Heinkel, K, and Kimmig, J M, Zeitschrift für Gastroenterologie, 1971, 9, 331

${ }^{12}$ Heinkel, K, and Kimmig, J M, Zeitschrift für Gastroenterologie, 1972, 10, 393

${ }^{13}$ Paoluzi P, Italian fournal of Gastroenterology. In press.

(Accepted 13 September 1979)

\section{Incidence of malignant melanoma of the skin in England and Wales and its relationship to sunshine}

\section{A J SWERDLOW}

British Medical fournal, 1979, 2, 1324-1327

\section{Summary and conclusions}

In most of England and Wales the incidence of malignant melanoma of the skin has risen rapidly in recent years, especially in women. Mean incidences in the 14 English health regions and Wales correlated negatively with latitude and positively with hours of sunshine, suggesting that exposure to sunshine was an important causal factor. Male and female incidences within a region tended to show similar yearly fluctuations, implying a common factor affecting the incidence in both men and women with a short latent period of action.

This factor may be exposure to sunshine, which may cause melanoma after an induction period of about two years; for women the incidence of melanoma in the regions of England and Wales correlated positively with hours of sunshine two years earlier.

\section{Introduction}

In white populations in recent years melanoma has accounted for most of the deaths from skin cancer, and the incidence of melanoma and its mortality have been rising faster than rates for any other cancer except, in some countries, lung cancer.

Epidemiological evidence indicates that exposure to sunlight may be an important causal factor in skin melanoma, ${ }^{12}$ although this is disputed. ${ }^{2}$ The evidence is less complete than that for the relationship between sun exposure and squamous-cell skin carcinomas. ${ }^{3}$ Recent reports ${ }^{4}{ }^{5}$ show an increased incidence of melanoma about two years after periods of increased sunspot activity. The rising trend in incidence may also be due to some extent to sunlight exposure. Concern has been expressed that the increasing use of fluorocarbon aerosol propellants and refrigerants and supersonic air travel may increase the shortwavelength ultraviolet (UV) radiation reaching the earth's surface and thus lead to an increase in the incidence of skin cancer. ${ }^{6}$

This paper explores the rising incidence of malignant melanoma of the skin and the nature of the relationship between sun exposure and the occurrence of melanoma, based on 24 years' data for the Oxford Region and rather fewer years for the rest of England and Wales.

Oxford Regional Health Authority, Headington, Oxford A J SWERDLOW, MA, BM, senior registrar in community medicine
Method

INCIDENCE OF MALIGNANT MELANOMA OF THE SKIN

For Oxford Region* residents directly age-standardised sex-specific annual incidence rates for 1952-75 were calculated using the 1961 Oxford Region population as the standard. Incidence data were obtained from the Oxford Cancer Registry and age-specific population data for 1955-74 from published sources. ${ }^{7}$ The age distributions of the population were estimated for 1952-54 and 1975, for which the data were not yet published.

The long series of incidence data obtained for Oxford Region were not available for other regions of England and Wales; the longest series available were crude incidence rates for 1955-69 in the Southwestern Region ${ }^{8}$ and crude rates for 1962-70 in the other regions and in England and Wales overall. ${ }^{9}$

For each set of data the mean incidence, the rate of increase in incidence (slope of the linear regression line of incidence on year) and the incidence expected in each year on the basis of linear regression of incidence on year were calculated.

\section{SUNSHINE}

For each region the measurements of mean daily hours of bright sunshine used were those recorded at the meteorological office "District values station"10 nearest to the main population centre(s) of each region. In the South-western Region no one station was representative and therefore the mean of data for two stations was adopted. For Wales a station in mid-Wales had to be used since complete data for 1960-8 were not available for any station in south Wales (where most of the population live). For England and Wales overall hours of sunshine were obtained from the Registrar General's Statistical Review of England and Wales. ${ }^{11}$

\section{CORRELATIONS}

For each region, for men and for women separately, the mean incidence and the rate of increase in incidence were correlated with the latitude representative of the main population centre(s) of the region and with hours of sunshine in the region two years earlier (the most likely induction period ${ }^{4}{ }^{5}$ ). To examine the extent to which male and female rates fluctuated together from year to year when longer-term trends were discounted, the correlation was calculated for each region between the deviations of male incidence rates in each year from male linear regression expectation and the deviations of the female rates for the same years from female linear regression expectations.

To test whether, when longer-term trends were discounted, hours of sunshine affected the incidence of melanoma two years later the correlation was calculated between the annual deviations from linear regression expectation of melanoma incidence and the deviation from linear regression expectation of annual hours of sunshine two

*Throughout, the Oxford Region refers to the area covered by the Oxford Regional Hospital Board in 1952-73 and that covered by the Oxford Regional Health Authority in 1974 and 1975. The difference between these areas is small and unlikely to have affected the results substantially. 